\title{
Auxin and Cytokinin Interplay during Leaf Morphogenesis and Phyllotaxy
}

\author{
Sajid Hussain ${ }^{1,2,3,+}\left(\mathbb{D}\right.$, Satyabrata Nanda ${ }^{2,4,+}{ }^{-}$, Junhua Zhang ${ }^{2}$, Muhammad Ishaq Asif Rehmani ${ }^{5}{ }^{(}$, \\ Muhammad Suleman ${ }^{3}$, Gaojie Li ${ }^{1, *}$ (D) and Hongwei Hou ${ }^{1, * \text { (D) }}$ \\ 1 The Key Laboratory of Aquatic Biodiversity and Conservation of Chinese Academy of Sciences, Institute of \\ Hydrobiology, Chinese Academy of Sciences, Wuhan 430072, China; hussainsajid@caas.cn \\ 2 State Key Laboratory of Rice Biology, China National Rice Research Institute, Hangzhou 310006, China; \\ sbn.satyananda@gmail.com (S.N.); zhangjunhua@caas.cn (J.Z.) \\ 3 Soil and Water Testing Laboratory, Marketing Division, Pak Arab Fertilizer Limited, Multan 66000, Pakistan; \\ sulemanquresi@yahoo.com \\ 4 MS Swaminathan School of Agriculture, Centurion University of Technology and Management, \\ Odisha 761200, India \\ 5 Department of Agronomy, Ghazi University, Dera Ghazi Khan 32200, Pakistan; mrehmani@gudgk.edu.pk \\ * Correspondence: ligaojie@ihb.ac.cn (G.L.); houhw@ihb.ac.cn (H.H.) \\ + Equal Contributions.
}

Citation: Hussain, S.; Nanda, S.;

Zhang, J.; Rehmani, M.I.A.; Suleman,

M.; Li, G.; Hou, H. Auxin and

Cytokinin Interplay during Leaf Morphogenesis and Phyllotaxy.

Plants 2021, 10, 1732

https://doi.org/10.3390/plants10081732

\begin{abstract}
Auxins (IAA) and cytokinins (CKs) are the most influential phytohormones, having multifaceted roles in plants. They are key regulators of plant growth and developmental processes. Additionally, their interplay exerts tight control on plant development and differentiation. Although several reviews have been published detailing the auxin-cytokinin interplay in controlling root growth and differentiation, their roles in the shoot, particularly in leaf morphogenesis are largely unexplored. Recent reports have provided new insights on the roles of these two hormones and their interplay on leaf growth and development. In this review, we focus on the effect of auxins, CKs, and their interactions in regulating leaf morphogenesis. Additionally, the regulatory effects of the auxins and CKs interplay on the phyllotaxy of plants are discussed.
\end{abstract}

Keywords: leaf formation; leaf arrangement; phytohormonal crosstalk; plant development

\section{Introduction}

Most of the higher plants owe their evolutionary fitness partially to their continuous network of interconnected vascular cells [1]. This network of cells provides structural scaffolding for the plant organs and ensures efficient transport of the water, minerals, hormones, and photosynthesis. The highly predictable and characteristic vascular patterns are tissue-specific in many species, suggesting a genetically based development process. Plants are constantly exposed to the environment due to lack of mobility, which in turn evolved the plants with exceptional survival strategies and developmental plasticity. Plant hormones, also known as phytohormones, play crucial roles in plant development and architecture modulation. More often, phytohormone pathways are complex but fine-tuned and share cross paths with other hormonal pathways. Two such phytohormones with vital roles in plants are auxins and cytokinins (CKs), and their biosynthesis pathways are well characterized in plants [2]. Auxins and CKs regulate the key physiological processes in plants by acting both antagonistically and synergistically [3]. For instance, the development of shoot meristems by the proliferation and differentiation of meristematic cells is regulated by the antagonistic interactions of auxins and CKs [4]. In contrast, plant growth and development can be modulated by the synergistic inputs of auxins and CKs [5].

Moreover, the in-depth analysis of auxins and CKs pathways has revealed that multiple players are involved in the crosstalk of these two hormones, fine-tuning their levels of auxins and cytokinins in plants [6]. The cytokinins biosynthesis is positively modulated 
by auxins via direct control of the ISOPENTENYL TRANSFERASE (IPT) genes transcript accumulations, which is mediated by the AUXIN RESPONSE FACTOR 19 (ARF19) transcription factor [5]. Similarly, the auxin-mediated transcriptional control of CYTOKININ RESPONSE FACTOR 2 (CRF2) by AUXIN RESPONSE FACTOR 5 (ARF5) can regulate the cytokinin pathway [7]. On the other hand, CKs manage the auxin distributions in plant cells by coordinating the influx and efflux carrier expressions. For example, transcription and translational activations of AUXIN/LIKE AUX (Aux/LAX) genes and PIN-FORMED (PIN) family genes are regulated by CKs [8,9]. As both auxins and CKs are crucial for cell proliferation and the development of organs in plants, characterizing their interplay becomes even more important. In this regard, the available literature with the recent findings sheds light on the involvement of both auxin and cytokinin pathway genes in leaf development in plants. However, the available literature is not sufficient for understanding the underlying molecular mechanisms $[6,10]$.

In plants, the formation of leaves is a continuous developmental process [11]. Leaves are crucial plant organs having highly organized functions, such as photosynthesis and respiration. In addition, the leaf structures and arrangements vary within and among plant species. It is confirmed that auxins contribute towards leaf development, including leaf initiation, blade development, and compound leaf patterning [12]. Similarly, auxin and CKs play important roles in many aspects of plant growth and development; particularly in the formation of meristem cells, which are vital to establishing the whole plant body [13]. CKs control several key developmental functions in plants, such as the regulation of shoot apical meristem (SAM) to leaf senescence. Further, the SAM is formed during the embryogenesis process, from which almost all of the aerial parts of a plant are developed. Cell division and cell differentiation actively occur in SAM. SAM is subdivided into various regions such as central, peripheral, and rib zones. Among these zones, the peripheral zone of the SAM is responsible for leaf primordial origination, which is replaced by cell division in both the peripheral zone itself and the central zone [13-15].

To elucidate this complex role of cytokinin in leaf development, temporal CK levels were investigated in the leaf of Arabidopsis. At the cell proliferation phase, CKs are needed to maintain cell proliferation by blocking the transition to cell expansion and the onset of photosynthesis. As a result, a CK excess at the cell expansion phase results in the increased leaf and rosette size, enhanced by a higher cell expansion rate, yielding higher shoot biomass. Further, the proteome profiling studies revealed that the stimulation of primary metabolism by $\mathrm{CK}$ in line with an increased sugar content increased the turgor pressure, representing the driving force of cell expansion. Therefore, the developmental timing of CK content fluctuations, together with tight control of primary metabolism, is a key factor mediating transitions from cell proliferation to cell expansion in leaves [16]. However, the precise mechanism behind vein pattern formation in plant leaves is not well known.

In this review, we discuss how auxins and CKs play roles in controlling the development and differentiation of leaves. We summarize recent progress in understanding how auxins and CKs signaling and their interactions regulate leaf morphogenesis. Finally, we have proposed a conceptual model depicting the auxins and CKs signal-mediated regulation of the leaf development.

\section{General Leaf Development Mechanism}

In leaves, the vascular tissue is derived from elongated precursor cells called procambium, which is formed from the undifferentiated ground meristem (GM) cell population and later differentiates into vascular elements, i.e., xylem and phloem [17]. During this process, the leaf is expanding through cell divisions, which slows down and stops first in the distal, and then, in the proximal part of the leaf [18]. This results in the formation of larger vascular bundles in the proximal regions of the leaf, even along the same strand [19]. Strands are often categorized into three vein orders: the primary veins (the midvein) are considered as the linear procambium or vascular strand approximately along the midline, secondary veins are those vascular strands (procambium) connected to the midvein, and 
tertiary veins are connected to secondary vein but not the midvein, while quaternary veins are connected to tertiary veins but not the mid-vein nor secondary veins.

To better understand the development of procambium, several vascular-specific reporter genes have been examined in the developmental series. The ET1335::GUS and AtHB8::GUS expression lines are reliable markers of procambium and both pre-procambium and procambium, respectively. They have revealed the patterns in the procambium development and differentiation in the Arabidopsis first leaf [17]. Based on AtHB-8 expression, the pre-procambia secondaries develop acropetally, that is, from the mid-vein to the tip. Based on the procambium cell diagnostic traits (i.e., cell elongation), pre-procambial secondaries differentiate into procambium either rapidly or simultaneously relative to all other cells of the same strand [17]. The fact that strands of AtHB8 include either procambium or GM but never both in the same strand supports this conclusion [17].

In the first leaf, the formation of the vein orders follows a relatively consistent pattern based on the use of the above-mentioned marker lines and the appearance of the elongated procambium [17]. Between day 2 and day 2.5 (from germination), the leaf primordium lacks any sign of procambial cells. On day 3 , procambium appears along the midline, forming the presumptive midvein. As the leaf continues to elongate, these procambial cells continue to divide $[19,20]$, thus ensuring vascular continuity in the growing organ. The first two secondary veins appear on day 5 as arches that join at the tip of the midline procambium, forming presumptive areoles (intercostal areas). On day 5.5, two additional arches of secondary procambia appear, forming presumptive areoles below the previous two. On day 7, the primordium is $0.7 \mathrm{~mm}$ long. On day 8 , an additional pair of secondaries appears in the most proximal region. Tertiary procambium is first seen on day 7 within the central areoles and appears in the more newly formed proximal areoles at day 8. Similar observations have been made by Baima et al. [21].

In all vein orders, differentiation into the xylem can be easily seen by lignification approximately two days after procambia strand formation [17] and generally occurs in the meristematic zones [19]. By day 21, all growth and vascular differentiation of the two first node leaves have been completed [22]. Subsequent rosette leaves are larger and have an increasing amount of vasculature. However, the venation density and the number of branch points per unit area remain relatively constant.

\section{Auxin and Cytokinin Biosynthesis: Convergence and Divergence}

\subsection{Auxin Biosynthesis in Plant}

Indole-3-acetic acid (IAA) plays a key role in plants and is mainly synthesized from the amino acid tryptophan (Trp). The first established complete Trp-dependent auxin biosynthesis pathway has two chemical steps which are essential in the plant kingdom (Figure 1). The first step is the removal of the amino group from Trp by the Tryptophan Aminotransferase of ARABIDOPSIS (TAA) family of transmission to generate indol-3-pyruvate acid (IPA). The second step is the conversion to produce IAA by YUCCA (YUC) family [23].

However, very little is known about auxin biosynthesis in plants due to its complexity [24]. With the help of genetic and biochemical approaches, new auxin biosynthesis pathways have been identified. IAA biosynthesis depends on many pathways; IAA can be released by cleavage of IAA conjugates: IAA-amino acids, IAA-methyl ester, and IAAsugar hydrolytic. Moreover, plant species vary in nature to produce or optimize their IAA biosynthesis. IAA biosynthesis occurs through Trp by the IPA in microbes. This IPA pathway uses similar enzymes to the IPA pathway in plants. The IAA biosynthesis is also influenced by various developmental and environmental conditions $[25,26]$. For instance, changes in the light quality received by plants can trigger a series of developmental responses known as shade avoidance syndrome. During shade avoidance, IPA is rapidly synthesized from Trp to ensure elevated auxin biosynthesis [26]. Similarly, a local auxin biosynthesis source can modulate the auxin redistribution and gradient homeostasis, and thus, can regulate the cellular morphogenesis [25]. 


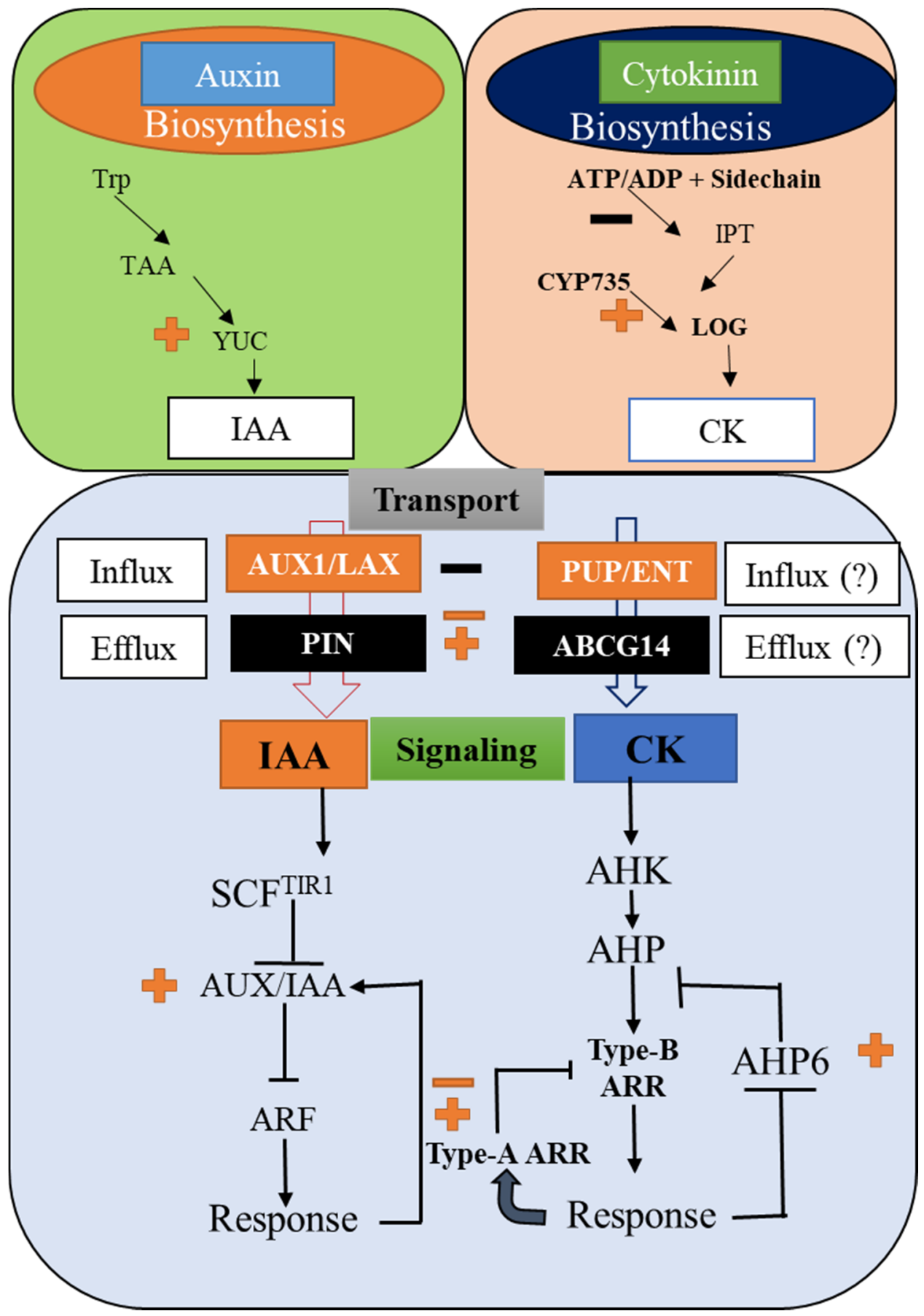

Figure 1. A schematic diagram depicting the biosynthesis, transport, and signaling of auxin and cytokinin in plants. Solid lines represent the established regulatory connections, whereas the dashed line indicates the possible connection. Line ending with a crossed line indicates the negative regulations.

\subsection{Cytokinin Biosynthesis in Plant}

CKs were named after their biological function, e.g., cytokinesis or cell division. Later, it was discovered that cytokinins are involved in many other plant physiological processes apart from cell division [27]. In CK biosynthesis, the first step is catalyzed by the ISOPENTENYLTRANSFERASE (IPT) enzyme that adds a prenyl moiety onto ATP / ADP forming the N6-isopentenyladenine (iP) ribosides [28]. The newly formed iP ribosides can subsequently be converted to trans-zeatin (tZ)-type cytokinins by the cytochrome P450 enzymes (CYP735A1/CYP735A2) via the hydroxylation of the isoprenoid side chains [29]. 
Further, the LONELY GUY (LOG) family enzymes catalyze the conversion of cytokinin ribosides into free and active forms of CKs [30]. Much like auxin, the CK levels can also be decreased via conjugation, mostly with glucose [31]. The glucosyl conjugates of CKs are inactive, which can either be reversible or irreversible [32,33]. In addition, enzymatic cleavage of $\mathrm{CKs}$ to form $\mathrm{tZ}$ - and iP-type CKs can be another type of regulation to reduce the CK concentrations in plants $[34,35]$. CKs also display differential spatial and temporal expression and localization, giving rise to $\mathrm{CK}$ asymmetries that in turn regulate cellular differentiation and development [36,37].

On the other hand, plant CK signaling elements are encoded by a small gene family with overlapping functions [38,39]. Three well-studied cytokinin receptors are the ARABIDOPSIS HISTIDINE KINASE 2 (AHK2), AHK3, and CRE1/WOL/AHK4, containing multiple conserved domains, including a cytokinin binding CHASE domain, a histidine kinase domain, and a receiver domain $[40,41]$. The plant CK receptors are mostly located in the endoplasmic reticulum lumen, suggesting it to be the primary site of CK binding [42,43]. Although the key players facilitating the cellular transport of CK are not yet fully explored, some of them, including the ATP binding cassette transporters, nucleoside transporter proteins, and purine permeases have been identified to be involved in CK transport [44-46]. Recent reports have revealed the participation of new players in the CK signaling contributing towards the plant developments, including leaf morphogenesis. Moreover, the complex crosstalk in between auxins and CKs plays a crucial role in determining the fate of the different organ developments in the plant, including leaf formation (Figure 1).

\section{Effects of Auxins and CKs in Regulating Their Signaling Pathways: An Inspection}

Auxins and CKs show complex interplays in plants and control various physiological activities. However, both these hormones can regulate the metabolism of one another in plants. Auxins have significant effects on CK metabolism and can exert control over its synthesis, transport, and action. For instance, the IPT gene expressions were influenced by the auxin levels in plants [47]. Later, it was discovered that the upregulation of $I P T$ genes by higher cellular auxin levels was mediated by SHORT HYPOCOTYL 2/INDOE-3ACETIC ACID 3 (SHY2/IAA3) [48]. Further, the action of auxins on IPT gene expressions was confirmed in plants, revealing the role of the shoot apex auxin in repressing these genes [49]. On the other hand, the treatment of auxins resulted in reduced CK biosynthesis in Arabidopsis [29,50].

Apart from regulating the $\mathrm{CK}$ biosynthesis, auxins can control its degradation by modulating the CYTOKININ OXIDASE/DEHYDROGENASE (CKX) gene family. In Arabidopsis, application of auxin down-regulated the expression of $C K X 2, C K X 4$, and $C K X 7$, whereas the treatment of 1-naphthylphthalamic acid (NPA), a polar transport inhibitor, strongly down-regulated $C K X 1$ and $C K X 6$ expressions [51]. In addition, auxin is reported to activate ARABIDOPSIS RESPONSE REGULATOR 7 (ARR7) and ARR15, which act as CK signaling inhibitors [52]. This report suggests the direct role of auxin acting antagonistically with plant CK signaling. The ARR7 and ARR15 expression in Arabidopsis corresponded more with the auxins, not CK signaling domain, which was later confirmed by the treatment of a synthetic auxin that resulted in the ARR domain expansion. Furthermore, treatment of naphthaleneacetic acid (NAA) onto the SAM resulted in the decreased expression of $A R R 7$ and ARR15. Contrastingly, in the arf5/mp mutant lines, the expressions of these genes were upregulated, suggesting the auxin-dependent regulation of the ARRs mediated by ARF5/MP (AUXIN RESPONSE FACTOR 5/MONOPTEROS) [4]. Similarly, CRF2, another response regulator in the auxins-CKs interplay, was identified to be a target of $A R F 5 / M P$ via microarray and ChIP (Chromatin Immunoprecipitation) analysis [7].

On the other hand, several reports confirmed that CKs could regulate auxin biosynthesis and cellular transport. For instance, the exogenous treatment of CKs onto Arabidopsis plants resulted in the auxin accumulations in young leaves and shoot apex. This was further validated in the ARR quadruple mutant (arr3 arr4 arr5 arr6) Arabidopsis lines, where the auxin biosynthesis was increased in many folds by the treatment of CKs [53]. Conversely, 
cytokinin treatment resulted in a significant decrease in IAA levels in the ARABIDOPSIS THALIANA HISTIDINE PHOSPHOTRANSFER PROTEIN (AHP) quadruple mutant (ahp1 ahp2 ahp3 ahp4) Arabidopsis plants [54,55]. IAA modulates the leaf veins development in Arabidopsis along with PIN1 auxin flux protein [56]. Similarly, the application of CKs resulted in the decreased expression levels of PIN1-4 and PIN7 in the shoot. Further, CKs treatment on pea plants caused the rapid transcript accumulation of two key players in the auxin transport, including PSPIN1 and PSAUX1 [57]. Getting some deeper insights into the auxins-CKs interplay, Zhang et al. [58] reported that CK-mediated regulation of auxin metabolisms, including the expression of the PIN class auxin transporters, might occur at a post-transcriptional level. Similar results were also concluded when $C K$ treatments resulted in the rapid decrease in the expression levels of PIN1 [58]. Additionally, the CK-mediated degradation of PIN1 was found to be robust in the single or double mutants of $a h k 2$ and ahk3, but compromised in the cre/ahk4 mutant [57]. Moreover, these findings suggest that the crosstalk between auxins and CKs is complex and regulate several key physiological processes, including plant growth and development (Figure 1, Table 1).

Table 1. Interactions of signaling pathway genes regulated by auxins and CKs.

\begin{tabular}{|c|c|c|c|}
\hline Gene Name & Biological Function & Regulation Effect & Reference \\
\hline \multicolumn{4}{|c|}{ Auxin Signaling Pathway Genes Regulated by CKs } \\
\hline AUX1 & Auxin influx transport & Upregulation & [57] \\
\hline PIN1, PIN2, PIN3, PIN4, PIN6, PIN7 & Auxin efflux transport & $\begin{array}{l}\text { Lateralization, Upregulation, } \\
\text { Tissue-specific downregulation }\end{array}$ & {$[54,59,60]$} \\
\hline IAA7, IAA13, IAA17, AMI1 & Auxin signaling & Downregulation & [61] \\
\hline AUXIN RESISTANT 1, 31 (AXR1, AXR3) & Auxin signaling & Upregulation & {$[53,62]$} \\
\hline CYP79B2 & Auxin biosynthesis & Upregulation & [53] \\
\hline YUCCA5, YUCCA6 & Auxin biosynthesis & Temporal expression regulation & [53] \\
\hline ANTHRANILATE SYNTHASE $\alpha 1$ (ASA1/WEI2) & Auxin precursor synthesis & Up-regulation & [53] \\
\hline GH3.17, GH3.9 & Auxin conjugation & Up-regulation & [53] \\
\hline $\begin{array}{c}\text { PHOSPHORIBOSYLANTHRANILATE } \\
\text { TRANSFERASE1 (PAT1)/TRYPTOPHAN } \\
\text { BIOSYNTHESIS1 (TRP1), INDOLE-3-GLYCEROL } \\
\text { PHOSPHATE SYNTHASE(IGPS), NITRILASE } 3 \text { (NIT3) }\end{array}$ & Auxin biosynthesis & Up-regulation & {$[53]$} \\
\hline \multicolumn{4}{|c|}{ CK Signaling Pathways Genes Regulated by Auxin } \\
\hline ARR7, ARR15 & Cytokinin signaling & Spatial expression regulation & {$[4,52]$} \\
\hline IPT1, IPT2 & Cytokinin biosynthesis & Downregulation & [49] \\
\hline IPT5, IPT7 & Cytokinin biosynthesis & Up-regulation & {$[47]$} \\
\hline CRF2, AHP6 & Cytokinin signaling & Up-regulation & {$[7,60]$} \\
\hline$C K X 2, C K X 4, C K X 7$ & Cytokinin degradation & Downregulation & [51] \\
\hline CYP735A & Cytokinin biosynthesis & Downregulation & [29] \\
\hline
\end{tabular}

\section{Role of Auxins-CKs Interactions on Leaf Development}

Both auxins and CKs play a crucial role in the plant leaf morphogenesis process. While regions of auxin response maxima are generated at the SAM before the leaf initiation, CKs govern the SAM maintenance $[63,64]$. The leaf initiation and the whole leaf morphogenesis process banks upon a complex yet delicate balance between auxins and CKs. The CKinduced expression of PIN1 and the response regulator protein $A B P H 1$ were found at the leaf initiation site in maize plants [64]. Further, the auxins-CKs interplay controls the SAM development, and phyllotaxy is highly induced by CKs and acts as a negative regulator of $\mathrm{CK}$ response [65]. Moreover, the possible synergistic and antagonistic nature of the auxinsCKs interactions plays a crucial role in determining the leaf initiation and development. For instance, ARR7 and ARR15 were negatively modulated by MONOPTEROS (MP) in Arabidopsis, whereas the $m p$ mutant lines with higher cytokinin concentrations rescued the floral initiation defect [65]. Interestingly, these results suggested that auxins and CKs interactions in Arabidopsis show synergism for the organ initiation process in the SAM while displaying antagonism in the roots [4]. In addition, the response regulator genes, such as ARR7 and ARR15, are involved in the positive control of SAM development and organ initiation in the vegetative meristems while exhibiting contrasting interactions with 
auxin in the meristem tissues. Similarly, AHP6 negatively regulates CK signaling and positively controls the Arabidopsis floral initiation downstream of auxin [66]. Although numerous reports suggest the positive role of auxin in controlling the leaf initiation, the role of CK is more complex depending on the plant species, developmental stage, and demands in-depth research to infer any firm conclusion [63] (Figure 2).

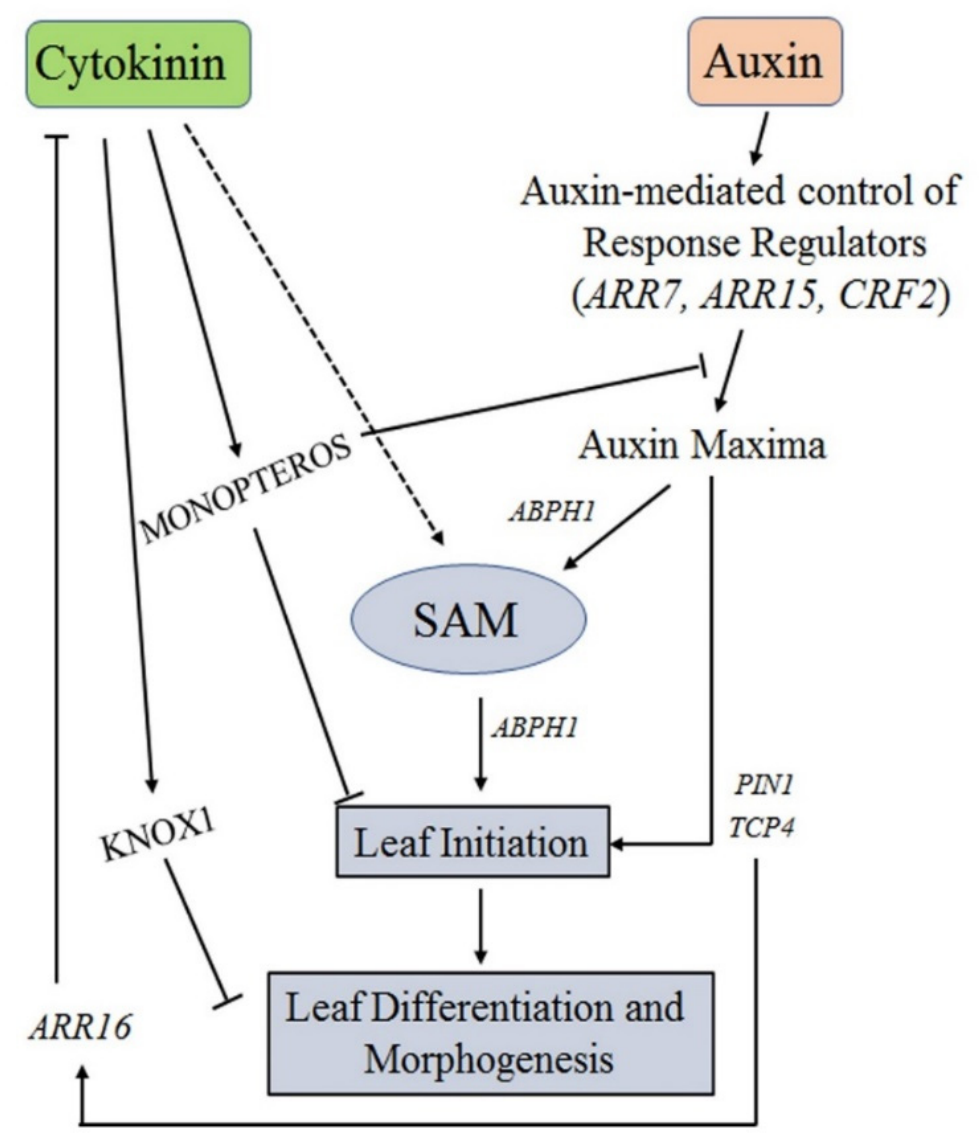

Figure 2. A model detailing the auxin and cytokinin interplay during leaf development and morphogenesis. Solid lines represent the established regulatory connections, whereas the dashed line indicates the possible connection. Line ending with a crossed line indicates the negative regulations.

Beyond leaf initiation, both auxins and CKs exert significant control in leaf serration and morphogenesis $[63,67]$. Auxins have been reported to regulate the leaf serration and leaflet formation and separation from the compound leaf primordia margins. The inhibition of auxin signaling or transport resulted in the development of simple leaves instead of compound leaves in Cardamine hirsuta [63]. Furthermore, several studies have confirmed the positive role of discrete auxin maxima in promoting leaflet initiation and growth [63,68-70]. The localization of PIN1 at leaflet initiation site, and the exogenous auxin treatments resulting in the ectopic leaflet initiation and lamina growth, further supported the positive role of auxin maxima in leaflet initiation and growth [70]. In contrast, CKs also influences the leaf morphogenesis and differentiation balance. For instance, accelerated cell expansion and premature cell proliferation termination were realized in the leaf primordia of Arabidopsis by increasing the CK degradation [71]. This suggests that CKs are involved in the delaying of the cell differentiation process in the leaf primordia. CKs were discovered to act downstream of the KNOTTEDLIKE HOMEOBOX (KNOX1) transcription factors in delaying the leaf maturation process [72,73]. KNOX1 genes are responsible for stem cell maintenance in the SAM and leaf development by regulating $\mathrm{CK}$ s and gibberellin (GA) $[74,75]$. It was reported that the KNOX1-CK/GA module also plays important role in 
the regulation of heterophylly (a typical representative of leaf plasticity) in many aquatic plants, such as Hygrophila difformis [76-78] and Rorippa aquatica [79,80]. More recently, an Arabidopsis transcription factor, CYTOKININ-RESPONSIVE GROWTH REGULATOR (CKG), was discovered to regulate the CK-dependent cell expansion and organ growth [81].

On the contrary, reducing the CK leaf sensitivity in Arabidopsis, the CIN (CINNATA)$T C P$ transcription factor-mediated leaf maturation process was accelerated. Further, $C I N$ can bind to the specific gene or promoter regions and induce the transcription of $\mathrm{CK}$ receptors and SHY2/IAA3. CIN actively participates in the auxin-CKs interplay in the leaf development by limiting the excessive cell proliferation process and ensure a flat-leaf surface. Additionally, CIN contributes to controlling the hormonal cross talks involved in cell proliferation and patterning in leaf morphogenesis [82]. Further, TCP4 induced the expression of ARR16 that encodes a CK response inhibitor [16]. Additionally, the prolonged morphogenetic activity of a tomato leaf was maintained and regulated by CKs [79]. Recently, Muszynski et al. [83] reported that mutation in Hairy Sheath Frayed1 (Hsf1), a gene regulating the leaf morphogenesis in maize, can alter leaf patterning via elevated $\mathrm{CK}$ signaling. Exogenous treatment of CKs onto the wild-type seedlings phenocopied the hsf1 leaf phenotypes. The above discussion shows that the interactions between auxins and CKs can determine the shoot and leaf developments. Moreover, auxins in lower concentrations tend to limit the CK-mediated physiological processes in plants [12]. Conversely, a surge in the CK levels can counteract the inhibitory effects of auxins and negatively regulate auxin signaling. Interestingly, at higher auxin and CK levels, the antagonism between these phytohormones is significantly suppressed. Moreover, the interactions between auxins and CKs are bidirectional, as both of them tend to control each other signaling cascades $[13,64]$. Conclusively, the complex yet fine-tuned interplay of auxins and CKs control the leaf initiation, proliferation, and morphogenesis process. Furthermore, other phytohormones and the auxins and CKs homeostasis play important roles in determining leaf development and differentiation.

\section{Effects of Auxin-Cytokinin Interplay in Phyllotaxy}

Phyllotaxy is the way of arrangement of leaves on a plant. Both auxins and CKs have significant control over the phyllotaxy in plants. A delicate balance between cell proliferation and differentiation is maintained in the SAM, which controls the shoot development in plants [84]. CKs play a vital role in the establishment and maintenance of the central zone cell division and proliferation. Once the cell differentiation is transferred from the central zone to the peripheral zone, the organ primordia (leaf primordia) can be formed [85]. This organogenesis and its subsequent differentiation into leaves form based on phyllotaxy [86]. Conversely, both organogenesis and phyllotaxy are tightly regulated by auxins. For instance, loss of function in CK signaling can alter SAM size, whereas the auxin signaling mutation can have huge effects on organogenesis [2]. Moreover, auxin flux in the SAM area significantly affects cell patterning. Both influx and efflux auxin carriers, such as AUX/LAX and PIN families, respectively participate in this patterning of SAM [87]. The auxin levels in the cell periphery are increased by the action of AUX/LAX carriers, while the polarly localized PIN proteins create an auxin-maximum at which the primordia initiation takes place [88]. AUX proteins can be poly-ubiquitinated by SCF ${ }^{\mathrm{TIRI}}$ complex, degraded through the $26 \mathrm{~S}$ proteasome proteolytic pathway and ARF proteins were then released to trigger changes in their target auxin response genes (Figure 1). At this site, the differential localization of PIN proteins creates auxin sinks, ensuring that additional primordial is not generated in the near vicinity [89]. The effective repositioning of the auxin maxima and the auxin sink establishes the phyllotaxy around SAM, ultimately controlling the leaf arrangements in plants [89].

The auxins-CKs interplay exerts dynamic controls in regulating the phyllotaxy. For example, CK mutants in Arabidopsis exhibited an altered meristem size and abnormal phyllotaxy [90]. Likewise, rice plants carrying a CK mutation produced an enlarged shoot meristem with altered phyllotaxy [91]. Interestingly, another family of genes known as 
ERECTA can act as a buffer in regulating the effects on SAM and phyllotaxy during the auxins and CKs interplay [92,93]. Moreover, several functional genomics studies have reported the critical effects of auxins-CKs crosstalk in regulating the plant phyllotaxy. For instance, loss of function of $A B P H 1$ resulted in the alternation of leaf phyllotaxy and yielded in the leaf initiations in opposite pairs rather than the alternative leaf structure in maize [92]. However, a detailed analysis of the $a b p h 1$ maize plants revealed that they contained decreased levels of both auxin and PIN1, suggesting that the phyllotaxy alternation might have been due to the combined effect of enlarged SAM and delayed leaf initiation. Similarly, mutating the negative modulator of CK AHP6 in Arabidopsis resulted in the altered phyllotaxis [85]. Interestingly, in the ahp6 lines, no enlargement of the meristem was seen, indicating that the control of leaf arrangements via auxins-CKs interplay is more complex and tightly regulated. Moreover, in-depth analysis in the ahp6 plants revealed that AHP6 regulates the spatiotemporal pattern of CKs at the peripheral regions of SAM, where depletion of CKs levels, in turn, elevates the auxin levels facilitating the proper phyllotactic patterning.

\section{Conclusions and Future Perspectives}

Auxins and CKs are two of the crucial phytohormones attributed to various key physiological processes. Their individual and synergistic or antagonistic roles are wellexplored in plants concerning plant growth and development. In addition, their crosstalk in regulating root development and vascular differentiation has been widely studied. However, there are only a handful of reports describing their effects in leaf morphogenesis. In this review, we have given a brief presentation on the role of auxin-cytokinin interplay in regulating the leaf morphogenesis process. From the discussion, both auxins and CKs exert tight control, independently and in association with each other, to regulate cell proliferation, cell expansion, and the transition between these processes during leaf development. Moreover, the fine-tune control of this complex interplay can efficiently regulate the leaf morphogenesis, differentiation, and arrangement in plants. Additionally, some key players, including the kinases like MAPKs and other regulatory factors, such as the non-coding RNAs in influencing the auxin-cytokinin interplay, are not fully understood during the leaf morphogenesis. Thus, in-depth analysis and functional genomics aided validations of this complex yet crucial interplay that could shed more light on the leaf morphogenesis in plants. Recently, the role of calcium ions $\left(\mathrm{Ca}^{2+}\right)$ in Phyllotaxy regulation has been unearthed [93]. The control of $\mathrm{Ca}^{2+}$ flux in cells and the $\mathrm{Ca}^{2+}$-mediated regulation of PIN proteins have provided new insights into auxin signaling. Finally, exploring the effects of other phytohormones in regulating the auxins-CKs interplay during leaf development can help us to better understand this complex process.

Recent advancements and discoveries on the roles of both auxins, CKs, and their cross talk in plant development have enabled us to understand the intertwined relationship between them. Further, the antagonistic and synergistic interactions of auxins and CKs in plants are now unearthed at a molecular and genetic level. With the discovery of new molecular players in the auxins and CKs interplay, the number of interaction points is also increasing in the interplay, thus making it more complex. To reduce this complexity and get a clearer picture of the auxins-CKs interplay, the role of computational biology and in silico simulation works could be of high value. Modeling the interactions and dynamics during the auxins-CKs interplay can provide new insights into the metabolisms, signaling, and transport of both hormones. However, many questions will remain unanswered without the wet-lab validation, such as what could be the principal role of cytokinin in plants concerning plant morphogenesis? Auxins have a central role in phytohormones crosstalk and plant development, and CKs actions in plants are more often coupled with auxin gradient. Could it be summarized that CKs function in plants in an auxin-dependent manner? In addition, how can auxins or CKs or their interplay contribute to the phenomenon of heterophylly and stress-associated phenotypic plasticity in plants? Moreover, delineating the complexities of the auxins-CKs interplay can provide satisfactory answers to these 
points. In the future, auxins and CKs can play an important role in heterophylly under salinity stress caused by osmotic stress.

Author Contributions: S.H. and S.N. have equally contributed to this work. H.H., S.H. and S.N conceived the idea. S.H., S.N. and H.H. prepared the first draft. S.H., S.N., J.Z., M.I.A.R. and H.H. revised the manuscript. M.S., G.L. and J.Z. contributed to making the figure and editing the article. All authors have made substantial direct or intellectual contributions to the work and have approved it for publication. All authors have read and agreed to the published version of the manuscript.

Funding: This research was supported by the National Key Research and Development Program of China (2017YFE0128800), the National Natural Science Foundation of China (31870384), and the International Partnership Program of the Chinese Academy of Sciences (152342KYSB20200021).

Acknowledgments: S.H. thanks the Chinese Academy of Sciences for the opportunity of writing this review paper. SN thanks Centurion University of Technology and Management for the necessary facilities and encouragement and extends his gratitude to Hou for the collaborative work. Because of space constraints, we apologize to all colleagues whose work and publications have not been mentioned and cited.

Conflicts of Interest: The authors declare no conflict of interest.

\begin{tabular}{|c|c|}
\hline ANTHRANILATE SYNTHASE $\alpha 1$ & ASA1 \\
\hline ARABIDOPSIS HISTIDINE KINASE 2 & AHK2 \\
\hline ARABIDOPSIS HISTIDINE PHOSPHOTRANSFERASE PROTEINS & AHP \\
\hline ARABIDOPSIS RESPONSE REGULATOR 7 & ARR7 \\
\hline AUXIN RESPONSE FACTOR 19 & ARF19 \\
\hline AUXIN/LIKE AUX & $A U X / L A X$ \\
\hline AUXIN RESISTANT 1, 3 & AXR1, AXR3 \\
\hline Chromatin Immunoprecipitation & CHIP \\
\hline class 1 KNOTTEDLIKE HOMEOBOX & KNOX1 \\
\hline CYTOCHROME P450 MONOOXYGENASE, FAMILY 735, SUBFAMILY A & CYP735A \\
\hline CYTOKININ OXIDASE/DEHYDROGENASE & CKX \\
\hline CYTOKININ RESPONSE FACTOR 2 & CRF2 \\
\hline Cytokinins & CKs \\
\hline Gibberellin & GA \\
\hline GRETCHEN HAGEN 3.17, 3.9 & GH3.17, H3.9 \\
\hline Ground meristem & GM \\
\hline INDOLE-3-GLYCEROL PHOSPHATE SYNTHASE & IGPS \\
\hline Indole-3-pyruvate acid & IPA \\
\hline Indole-3-acetic acid & IAA \\
\hline ISOPENTENYLTRANSFERASE & IPT \\
\hline LONELY GUY & LOG \\
\hline MONOPTEROS & $M P$ \\
\hline 1-naphthylphthalamic acid & NPA \\
\hline N6-isopentenyladenine & iP \\
\hline Naphthaleneacetic acid & NAA \\
\hline NITRILASE3 & NIT3 \\
\hline PHOSPHORIBOSYLANTHRANILATE TRANSFERASE1 & PAT1 \\
\hline PIN-FORMED & PIN \\
\hline Shoot apical meristem & SAM \\
\hline SHORT HYPOCOTYL2/Indole-3-acetic acid3 & SHY2/IAA3 \\
\hline trans-zeatin & $\mathrm{tZ}$ \\
\hline tryptophan & $\operatorname{Trp}$ \\
\hline TRYPTOPHAN AMINOTRANFERASE OF ARABIDOPSIS & $T A A$ \\
\hline 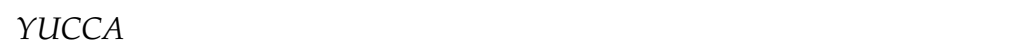 & YUC \\
\hline
\end{tabular}




\section{References}

1. Roth-Nebelsick, A.; Uhl, D.; Mosbrugger, V.; Kerp, H. Evolution and Function of Leaf Venation Architecture: A Review. Ann. Bot. 2001, 87, 553-566. [CrossRef]

2. Schaller, G.E.; Bishopp, A.; Kieber, J.J. The Yin-Yang of Hormones: Cytokinin and Auxin Interactions in Plant Development. Plant Cell 2015, 27, 44-63. [CrossRef]

3. Danilova, M.N.; Doroshenko, A.S.; Kudryakova, N.V.; Klepikova, A.V.; Shtratnikova, V.Y.; Kusnetsov, V.V. The Crosstalk Between Cytokinin and Auxin Signaling Pathways in the Control of Natural Senescence of Arabidopsis thaliana Leaves. Russ. J. Plant Physiol. 2020, 67, 1028-1035. [CrossRef]

4. Zhao, Z.; Andersen, S.U.; Ljung, K.; Dolezal, K.; Miotk, A.; Schultheiss, S.J.; Lohmann, J.U. Hormonal Control of the Shoot Stem-Cell Niche. Nat. Cell Biol. 2010, 465, 1089-1092. [CrossRef] [PubMed]

5. Yang, Z.; Liu, G.; Liu, J.; Zhang, B.; Meng, W.; Müller, B.; Hayashi, K.; Zhang, X.; Zhao, Z.; De Smet, I.; et al. Synergistic Action of Auxin and Cytokinin Mediates aluminum-induced Root Growth Inhibition in Arabidopsis. EMBO Rep. 2017, 18, 1213-1230. [CrossRef]

6. Hurný, A.; Cuesta, C.; Cavallari, N.; Ötvös, K.; Duclercq, J.; Dokládal, L.; Montesinos, J.C.; Gallemí, M.; Semerádová, H.; Rauter, T.; et al. Synergistic on Auxin and Cytokinin 1 Positively Regulates Growth and Attenuates Soil Pathogen Resistance. Nat. Commun. 2020, 11, 2170. [CrossRef] [PubMed]

7. Schlereth, A.; Möller, B.; Liu, W.; Kientz, M.; Flipse, J.; Rademacher, E.H.; Schmid, M.; Jürgens, G.; Weijers, D. Monopteros Controls Embryonic Root Initiation by Regulating a Mobile Transcription Factor. Nat. Cell Biol. 2010, 464, 913-916. [CrossRef]

8. Ruzicka, K.; Simaskova, M.; Duclercq, J.; Petrasek, J.; Zazimalova, E.; Simon, S.; Friml, J.; Van Montagu, M.C.E.; Benkova, E. Cytokinin Regulates Root Meristem Activity via Modulation of the Polar Auxin Transport. Proc. Natl. Acad. Sci. USA 2009, 106, 4284-4289. [CrossRef] [PubMed]

9. Šimášková, M.; O’Brien, J.A.; Khan-Djamei, M.; Van Noorden, G.; Ötvös, K.; Vieten, A.; De Clercq, I.; Van Haperen, J.M.A.; Cuesta, C.; Hoyerova, K.; et al. Cytokinin Response Factors Regulate PIN-FORMED Auxin Transporters. Nat. Commun. $2015,6,8717$. [CrossRef] [PubMed]

10. Hurný, A.; Benková, E. Methodological Advances in Auxin and Cytokinin Biology; Springer Science and Business Media LLC: Berlin, Germany, 2017; Volume 1569, pp. 1-29. [CrossRef]

11. Lee, Z.H.; Hirakawa, T.; Yamaguchi, N.; Ito, T. The Roles of Plant Hormones and Their Interactions with Regulatory Genes in Determining Meristem Activity. Int. J. Mol. Sci. 2019, 20, 4065. [CrossRef] [PubMed]

12. Xiong, Y.; Jiao, Y. The Diverse Roles of Auxin in Regulating Leaf Development. Plants 2019, 8, 243. [CrossRef]

13. Su, Y.-H.; Liu, Y.-B.; Zhang, X.-S. Auxin-Cytokinin Interaction Regulates Meristem Development. Mol. Plant 2011, 4, 616-625. [CrossRef] [PubMed]

14. Sablowski, R. The Dynamic Plant Stem Cell Niches. Curr. Opin. Plant Biol. 2007, 10, 639-644. [CrossRef] [PubMed]

15. Reddy, G.V. Live-Imaging Stem-Cell Homeostasis in the Arabidopsis Shoot Apex. Curr. Opin. Plant Biol. 2008, 11, 88-93. [CrossRef] [PubMed]

16. Skalák, J.; Vercruyssen, L.; Claeys, H.; Hradilová, J.; Cerny, M.; Novák, O.; Plačková, L.; Saiz-Fernández, I.; Skaláková, P.; Coppens, F.; et al. Multifaceted Activity of Cytokinin in Leaf Development Shapes Its Size and Structure in Arabidopsis. Plant J. 2019, 97, 805-824. [CrossRef] [PubMed]

17. Scarpella, E.; Meijer, A.H. Pattern Formation in the Vascular System of Monocot and Dicot Plant Species. New Phytol. 2004, 164, 209-242. [CrossRef] [PubMed]

18. Tsukaya, H. Leaf Development. Arab. Book 2002, 1, e0072. [CrossRef]

19. Kang, J.; Dengler, N. Vein Pattern Development in Adult Leaves of Arabidopsis thaliana. Int. J. Plant Sci. 2004, 165, 231-242. [CrossRef]

20. Donnelly, P.M.; Bonettaa, D.; Tsukaya, H.; Dengler, R.E.; Dengler, N.G. Cell Cycling and Cell Enlargement in Developing Leaves of Arabidopsis. Dev. Biol. 1999, 215, 407-419. [CrossRef]

21. Baima, S.; Possenti, M.; Matteucci, A.; Wisman, E.; Altamura, M.M.; Ruberti, I.; Morelli, G. The Arabidopsis ATHB-8 HD-Zip Protein Acts As a Differentiation-Promoting Transcription Factor of the Vascular Meristems. Plant Physiol. 2001, 126, 643-655. [CrossRef]

22. Candela, H.; Martínez-Laborda, A.; Micol, J.L. Venation Pattern Formation in Arabidopsis thaliana Vegetative Leaves. Dev. Biol. 1999, 205, 205-216. [CrossRef] [PubMed]

23. Zhao, Y. Auxin Biosynthesis. The Arabidopsis Book. Am. Soc. Plant 2014, 12, e0173.

24. Zhao, Y. Auxin Bionsynthesis and Its Role in Plant Development. Annu. Rev. Plant Biol. 2010, 2, 49-64. [CrossRef] [PubMed]

25. Ikeda, Y.; Men, S.; Fischer, U.; Stepanova, A.; Alonso, J.; Ljung, K.; Grebe, M. Local Auxin Biosynthesis Modulates GradientDirected Planar Polarity in Arabidopsis. Nat. Cell Biol. 2009, 11, 731-738. [CrossRef] [PubMed]

26. Tao, Y.; Ferrer, J.-L.; Ljung, K.; Pojer, F.; Hong, F.; Long, J.A.; Li, L.; Moreno, J.; Bowman, M.E.; Ivans, L.J.; et al. Rapid Synthesis of Auxin via a New Tryptophan-Dependent Pathway Is Required for Shade Avoidance in Plants. Cell 2008, 133, 164-176. [CrossRef]

27. Frébort, I.; Kowalska, M.; Hluska, T.; Frébortová, J.; Galuszka, P. Evolution of Cytokinin Biosynthesis and Degradation. J. Exp. Bot. 2011, 62, 2431-2452. [CrossRef] [PubMed]

28. Sakakibara, H. CYTOKININS: Activity, Biosynthesis, and Translocation. Annu. Rev. Plant Biol. 2006, 57, 431-449. [CrossRef] [PubMed] 
29. Takei, K.; Yamaya, T.; Sakakibara, H. Arabidopsis CYP735A1 and CYP735A2 Encode Cytokinin Hydroxylases That Catalyze the Biosynthesis of Trans-Zeatin. J. Biol. Chem. 2004, 279, 41866-41872. [CrossRef] [PubMed]

30. Kuroha, T.; Tokunaga, H.; Kojima, M.; Ueda, N.; Ishida, T.; Nagawa, S.; Fukuda, H.; Sugimoto, K.; Sakakibara, H. Functional Analyses of LONELY GUY Cytokinin-Activating Enzymes Reveal the Importance of the Direct Activation Pathway in AraBidopsis. Plant Cell 2009, 21, 3152-3169. [CrossRef] [PubMed]

31. Bajguz, A.; Piotrowska, A. Conjugates of Auxin and Cytokinin. Phytochemistry 2009, 70, 957-969. [CrossRef]

32. Hou, B.; Lim, E.-K.; Higgins, G.; Bowles, D.J. N-Glucosylation of Cytokinins by Glycosyltransferases of Arabidopsis thaliana. J. Biol. Chem. 2004, 279, 47822-47832. [CrossRef]

33. Mok, D.W.; Mok, M.C. Cytokinin Metabolism and Action. Annu. Rev. Plant Physiol. Plant Mol. Biol. 2001, 52, 89-118. [CrossRef]

34. Schmülling, T.; Werner, T.; Riefler, M.; Krupková, E.; Bartrina y Manns, I. Structure and Function of Cytokinin Oxidase/DeHydrogenase Genes of Maize, Rice, Arabidopsis and Other Species. J. Plant Res. 2003, 116, 241-252. [CrossRef] [PubMed]

35. Werner, T.; Köllmer, I.; Bartrina, I.; Holst, K.; Schmülling, T. New Insights into the Biology of Cytokinin Degradation. Plant Biol. 2006, 8, 371-381. [CrossRef] [PubMed]

36. Kowalska, M.; Galuszka, P.; Frébortová, J.; Šebela, M.; Béres, T.; Hluska, T.; Šmehilová, M.; Bilyeu, K.D.; Frébort, I. Vacuolar and Cytosolic Cytokinin Dehydrogenases of Arabidopsis thaliana: Heterologous Expression, Purification and Properties. Phytochemistry 2010, 71, 1970-1978. [CrossRef]

37. Gao, S.; Fang, J.; Xu, F.; Wang, W.; Sun, X.; Chu, J.; Cai, B.; Feng, Y.-Q.; Chu, C. Cytokinin Oxidase/Dehydrogenase4 Integrates Cytokinin and Auxin Signaling to Control Rice Crown Root Formation. Plant Physiol. 2014, 165, 1035-1046. [CrossRef] [PubMed]

38. Du, L.; Jiao, F.; Chu, J.; Jin, G.; Chen, M.; Wu, P. The Two-Component Signal System in Rice (Oryza Sativa L.): A Genome-Wide Study of Cytokinin Signal Perception and Transduction. Genomics 2007, 89, 697-707. [CrossRef] [PubMed]

39. Pils, B.; Heyl, A. Unraveling the Evolution of Cytokinin Signaling. Plant Physiol. 2009, 151, 782-791. [CrossRef] [PubMed]

40. Higuchi, M.; Pischke, M.S.; Mähönen, A.P.; Miyawaki, K.; Hashimoto, Y.; Seki, M.; Kobayashi, M.; Shinozaki, K.; Kato, T.; Tabata, S.; et al. In Planta Functions of the Arabidopsis Cytokinin Receptor Family. Proc. Natl. Acad. Sci. USA 2004, 101, 8821-8826. [CrossRef] [PubMed]

41. Nishimura, C.; Ohashi, Y.; Sato, S.; Kato, T.; Tabata, S.; Ueguchi, C. Histidine Kinase Homologs That Act As Cytokinin Receptors Possess Overlapping Functions in the Regulation of Shoot and Root Growth in Arabidopsis. Plant Cell 2004, 16, $1365-1377$. [CrossRef]

42. Caesar, K.; Thamm, A.M.K.; Witthöft, J.; Elgass, K.; Huppenberger, P.; Grefen, C.; Horak, J.; Harter, K. Evidence for the LoCalization of the Arabidopsis Cytokinin Receptors AHK3 and AHK4 in the Endoplasmic Reticulum. J. Exp. Bot. 2011, 62, 5571-5580. [CrossRef] [PubMed]

43. Wulfetange, K.; Lomin, S.N.; Romanov, G.A.; Stolz, A.; Heyl, A.; Schmülling, T. The Cytokinin Receptors of Arabidopsis Are Located Mainly to the Endoplasmic Reticulum. Plant Physiol. 2011, 156, 1808-1818. [CrossRef] [PubMed]

44. Hirose, N.; Takei, K.; Kuroha, T.; Kamada-Nobusada, T.; Hayashi, H.; Sakakibara, H. Regulation of Cytokinin Biosynthesis, Compartmentalization and Translocation. J. Exp. Bot. 2007, 59, 75-83. [CrossRef] [PubMed]

45. Ko, D.; Kang, J.; Kiba, T.; Park, J.; Kojima, M.; Do, J.; Kim, K.Y.; Kwon, M.; Endler, A.; Song, W.; et al. Arabidopsis ABCG14 Is Essential for the Root-Toshoot Translocation of Cytokinin. Proc. Natl. Acad. Sci. USA 2014, 111, 7150-7155. [CrossRef]

46. Zhang, K.; Novak, O.; Wei, Z.; Gou, M.; Zhang, X.; Yu, Y.; Yang, H.; Cai, Y.; Strnad, M.; Liu, C.-J. Arabidopsis ABCG14 Protein Controls the Acropetal Translocation of Root-Synthesized Cytokinins. Nat. Commun. 2014, 5, 3274. [CrossRef] [PubMed]

47. Miyawaki, K.; Matsumoto-Kitano, M.; Kakimoto, T. Expression of Cytokinin Biosynthetic Isopentenyltransferase Genes in Arabidopsis: Tissue Specificity and Regulation by Auxin, Cytokinin, and Nitrate. Plant J. 2004, 37, 128-138. [CrossRef] [PubMed]

48. Ioio, R.D.; Nakamura, K.; Moubayidin, L.; Perilli, S.; Taniguchi, M.; Morita, M.T.; Aoyama, T.; Costantino, P.; Sabatini, S. A Genetic Framework for the Control of Cell Division and Differentiation in the Root Meristem. Science 2008, 322, 1380-1384. [CrossRef] [PubMed]

49. Tanaka, M.; Takei, K.; Kojima, M.; Sakakibara, H.; Mori, H. Auxin Controls Local Cytokinin Biosynthesis in the Nodal Stem in Apical Dominance. Plant J. 2006, 45, 1028-1036. [CrossRef] [PubMed]

50. Nordström, A.; Tarkowski, P.; Tarkowska, D.; Norbaek, R.; Åstot, C.; Dolezal, K.; Sandberg, G. Auxin Regulation of Cytokinin Biosynthesis in Arabidopsis thaliana: A Factor of Potential Importance for Auxin-Cytokininregulated Development. Proc. Natl. Acad. Sci. USA 2004, 101, 8039-8044. [CrossRef] [PubMed]

51. Jones, B.; Gunneras, S.A.; Petersson, S.V.; Tarkowski, P.; Graham, N.; May, S.; Dolezal, K.; Sandhberg, G.; Ljung, K. Cytokinin Regulation of Auxin Synthesis in Arabidposis Involves a Homeostatic Feedback Loop Regulated via Auxin and Cytokinin Signal Transduction. Plant Cell 2010, 22, 2956-2969. [CrossRef] [PubMed]

52. El-Showk, S.; Ruonala, R.; Helariutta, Y. Crossing Paths: Cytokinin Signalling and Crosstalk. Development 2013, 140, 1373-1383. [CrossRef]

53. Laplaze, L.; Benkova, E.; Casimiro, I.; Maes, L.; Vanneste, S.; Swarup, R.; Weijers, D.; Calvo, V.; Parizot, B.; Herrera-Rodriguez, M.B.; et al. Cytokinins Act Directly on Lateral Root Founder Cells to Inhibit Root Initiation. Plant Cell 2008, 19, 3889-3900. [CrossRef]

54. Hou, H.; Jessica, E.; James, M.; Elizbath, A.S. FORKED1 Encodes a PH Domain Protein That Is Required for PIN1 Localization in Developming Leaf Veins. Plant J. 2010, 63, 960-973. [CrossRef] 
55. Kalousek, P.; Buchtová, D.; Balla, J. Cytokinin and Polar Transport of Auxin in Axillary Pea Buds. Acta Univ. Agri Cult. Et Silvic. Mendel. Brun. LVIII 2010, 58, 79-88. [CrossRef]

56. Zhang, W.; To, J.P.C.; Cheng, C.-Y.; Schaller, G.E.; Kieber, J.J. Type-A Response Regulators Are Required for Proper Root Apical Meristem Function through Post-Transcriptional Regulation of PIN Auxin Efflux Carriers. Plant J. 2011, 68, 1-10. [CrossRef] [PubMed]

57. Marhavy, P.; Bielach, A.; Abas, L.; Abuzeineh, A.; Duclercq, J.; Tanaka, H.; Pařezová, M.; Petrasek, J.; Friml, J.; Kleine-Vehn, J.; et al. Cytokinin Modulates Endocytic Trafficking of PIN1 Auxin Efflux Carrier to Control Plant Organogenesis. Dev. Cell 2011, 21, 796-804. [CrossRef] [PubMed]

58. Bishopp, A.; Help, H.; El-Showk, S.; Weijers, D.; Scheres, B.; Friml, J.; Benkova, E.; Mahonen, A.P.; Helariutta, Y. A Mutually Inhibitory Interaction between Auixin and Cytokinin Specifies Vascular Pattern in Roots. Curr. Biol. 2011, 21, 917-926. [CrossRef] [PubMed]

59. Brenner, W.G.; Schmülling, T. Transcript Profiling of Cytokinin Action in Arabidopsis Roots and Shoots Discovers Largely Similar But Also Organ-Specific Responses. BMC Plant Biol. 2012, 12, 112. [CrossRef] [PubMed]

60. Biedroń, M.; Banasiak, A. Auxin-Mediated Regulation of Vascular Patterning in Arabidopsis thaliana Leaves. Plant Cell Rep. 2018, 37, 1215-1229. [CrossRef]

61. Heisler, M.G.; Byrne, M.E. Progress in Understanding the Role of Auxin in Lateral Organ Development in Plants. Curr. Opin. Plant Biol. 2020, 53, 73-79. [CrossRef]

62. Lee, B.-H.; Yu, S.-I.; Jackson, D. Control of Plant Architecture: The Role of Phyllotaxy and Plastochron. J. Plant Biol. 2009, 52, 277-282. [CrossRef]

63. Kieber, J.J.; Schaller, G.E. Cytokinins. Arab. Book 2014, 12, e0168. [CrossRef] [PubMed]

64. Besnard, F.; Refahi, Y.; Morin, V.; Marteaux, B.; Brunoud, G.; Chambrier, P.; Rozier, F.; Mirabet, V.; Legrand, J.; Lainé, S.; et al. Cytokinin Signalling Inhibitory Fields Provide Robustness to Phyllotaxis. Nat. Cell Biol. 2014, 505, 417-421. [CrossRef] [PubMed]

65. Bilsborough, G.D.; Runions, A.; Barkoulas, M.; Jenkins, H.W.; Hasson, A.; Galinha, C.; Laufs, P.; Hay, A.; Prusinkiewicz, P.; Tsiantis, M. Model for the Regulation of Arabidopsis thaliana Leaf Margin Development. Proc. Natl. Acad. Sci. USA 2011, 108, 3424-3429. [CrossRef] [PubMed]

66. DeMason, D.A.; Polowick, P.L. Patterns of DR5::GUS Expression in Organs of Pea (Pisum sativum). Int. J. Plant Sci. 2009, $170,1-11$. [CrossRef]

67. Koenig, D.; Bayer, E.; Kang, J.; Kuhlemeier, C.; Sinha, N. Auxin Patterns Solanum Lycopersicum Leaf Morphogenesis. Development 2009, 136, 2997-3006. [CrossRef] [PubMed]

68. Ben-Gera, H.; Shwartz, I.; Shao, M.-R.; Shani, E.; Estelle, M.; Ori, N. ENTIRE and GOBLET Promote Leaflet Development in Tomato by Modulating Auxin Response. Plant J. 2012, 70, 903-915. [CrossRef] [PubMed]

69. Holst, K.; Schmülling, T.; Werner, T. Enhanced Cytokinin Degradation in Leaf Primordia of Transgenic Arabidopsis Plants Reduces Leaf Size and Shoot Organ Primordia Formation. J. Plant Physiol. 2011, 168, 1328-1334. [CrossRef] [PubMed]

70. Bharathan, G.; Goliber, T.E.; Moore, C.; Kessler, S.; Pham, T.; Sinha, N.R. Homologies in Leaf Form Inferred from KNOXI Gene Expression during Development. Science 2002, 296, 1858-1860. [CrossRef]

71. Bar, M.; Ori, N. Leaf Development and Morphogenesis. Development 2014, 141, 4219-4230. [CrossRef] [PubMed]

72. Shani, E.; Ben-Gera, H.; Shleizer-Burko, S.; Burko, Y.; Weiss, D.; Ori, N. Cytokinin Regulates Compound Leaf Development in Tomato. Plant Cell 2010, 22, 3206-3217. [CrossRef] [PubMed]

73. Li, G.; Hu, S.; Zhao, X.; Kumar, S.; Li, Y.; Yang, J.; Hou, H. Mechanisms of the Morphological Plasticity Induced by Phytohormones and the Environment in Plants. Int. J. Mol. Sci. 2021, 22, 765. [CrossRef] [PubMed]

74. Li, G.; Hu, S.; Yang, J.; Schultz, E.A.; Clarke, K.; Hou, H. Water-Wisteria As an Ideal Plant to Study Heterophylly in Higher Aquatic Plants. Plant Cell Rep. 2017, 36, 1225-1236. [CrossRef] [PubMed]

75. Li, G.; Hu, S.; Hou, H.; Kimura, S. Heterophylly: Phenotypic Plasticity of Leaf Shape in Aquatic and Amphibious Plants. Plants 2019, 8, 420. [CrossRef]

76. Li, G.; Hu, S.; Yang, J.; Zhao, X.; Kimura, S.; Schultz, E.A.; Hou, H. Establishment of an Agrobacterium Mediated Trans-Formation Protocol for the Detection of Cytokinin in the Heterophyllous Plant Hygrophila difformis (Acanthaceae). Plant Cell Rep. 2020, 39, 737-750. [CrossRef]

77. Nakayama, H.; Nakayama, N.; Seiki, S.; Kojima, M.; Sakakibara, H.; Sinha, N.; Kimura, S. Regulation of the KNOX-GA Gene Module Induces Heterophyllic Alteration in North American Lake Cress. Plant Cell 2014, 26, 4733-4748. [CrossRef] [PubMed]

78. Nakayama, H.; Sinha, N.R.; Kimura, S. How Do Plants and Phytohormones Accomplish Heterophylly, Leaf Phenotypic Plasticity, in Response to Environmental Cues. Front. Plant Sci. 2017, 8, 8. [CrossRef]

79. Park, J.; Lee, S.; Park, G.; Cho, H.; Choi, D.; Umeda, M.; Choi, Y.; Hwang, D.; Hwang, I. Cytokinin-Responsive Growth Regulator Regulates Cell Expansion and Cytokinin-Mediated Cell Cycle Progression. Plant Physiol. 2021, 186, 1734-1746. [CrossRef]

80. Das Gupta, M.; Aggarwal, P.; Nath, U. CINCINNATA in Antirrhinum majus Directly Modulates Genes Involved in Cytokinin and Auxin Signaling. New Phytol. 2014, 204, 901-912. [CrossRef] [PubMed]

81. Efroni, I.; Han, S.-K.; Kim, H.J.; Wu, M.-F.; Steiner, E.; Birnbaum, K.D.; Hong, J.C.; Eshed, Y.; Wagner, D. Regulation of Leaf Maturation by Chromatin-Mediated Modulation of Cytokinin Responses. Dev. Cell 2013, 24, 438-445. [CrossRef] [PubMed] 
82. Muszynski, M.G.; Moss-Taylor, L.; Chudalayandi, S.; Cahill, J.; Del Valle-Echevarria, A.R.; Alvarez-Castro, I.; Petefish, A.; Sakakibara, H.; Krivosheev, D.M.; Lomin, S.N.; et al. The Maize Hairy Sheath Frayed1 (Hsf1) Mutation Alters Leaf Patterning through Increased Cytokinin Signaling. Plant Cell 2020, 32, 1501-1518. [CrossRef] [PubMed]

83. Kurepa, J.; Shull, T.E.; Smalle, J.A. Antagonistic Activity of Auxin and Cytokinin in Shoot and Root Organs. Plant Direct 2019,3 , e00121. [CrossRef] [PubMed]

84. Murray, J.; Jones, A.; Godin, C.; Traas, J. Systems Analysis of Shoot Apical Meristem Growth and Development: Integrating Hormonal and Mechanical Signaling. Plant Cell 2012, 24, 3907-3919. [CrossRef]

85. Kierzkowski, D.; Lenhard, M.; Smith, R.; Kuhlemeier, C. Interaction between Meristem Tissue Layers Controls Phyllotaxis. Dev. Cell 2013, 26, 616-628. [CrossRef] [PubMed]

86. Furutani, M.; Nakano, Y.; Tasaka, M. MAB4-Induced Auxin Sink Generates Local Auxin Gradients in Arabidopsis Organ for-Mation. Proc. Natl. Acad. Sci. USA 2014, 111, 1198-1203. [CrossRef] [PubMed]

87. Stoma, S.; Lucas, M.; Chopard, J.; Schaedel, M.; Traas, J.; Godin, C. Flux-Based Transport Enhancement As a Plausible Unifying Mechanism for Auxin Transport in Meristem Development. PLoS Comput. Biol. 2008, 4, e1000207. [CrossRef]

88. Bartrina, I.; Otto, E.; Strnad, M.; Werner, T.; Schmülling, T. Cytokinin Regulates the Activity of Reproductive Meristems, Flower Organ Size, Ovule Formation, and Thus Seed Yield in Arabidopsis thaliana. Plant Cell 2011, 23, 69-80. [CrossRef] [PubMed]

89. Itoh, J.I.; Hibara, K.I.; Kojima, M.; Sakakibara, H.; Nagato, Y. Rice DECUSSATE Controls Phyllotaxy by Affecting the Cy-Tokinin Signaling Pathway. Plant J. 2012, 72, 869-881. [CrossRef]

90. Uchida, N.; Shimada, M.; Tasaka, M. ERECTA-Family Receptor Kinases Regulate Stem Cell Homeostasis via Buffering Its Cytokinin Responsiveness in the Shoot Apical Meristem. Plant Cell Physiol. 2012, 54, 343-351. [CrossRef] [PubMed]

91. Chen, M.-K.; Wilson, R.L.; Palme, K.; Ditengou, F.A.; Shpak, E.D. ERECTA Family Genes Regulate Auxin Transport in the Shoot Apical Meristem and Forming Leaf Primordia. Plant Physiol. 2013, 162, 1978-1991. [CrossRef]

92. Lee, B.H.; Johnston, R.; Yang, Y.; Gallavotti, A.; Kojima, M.; Travençolo, B.A.N.; da, F. Costa, L.; Sakakibara, H.; Jackson, D. Studies of Aberrant Phyllotaxy1 Mutants of Maize Indicate Complex Interactions between Auxin and Cytokinin Signaling in the Shoot Apical Meristem. Plant Physiol. 2009, 150, 205-216. [CrossRef] [PubMed]

93. Lamport, D.T.A.; Tan, L.; Held, M.; Kieliszewski, M.J. Phyllotaxis Turns Over a New Leaf-A New Hypothesis. Int. J. Mol. Sci. 2020, 21, 1145. [CrossRef] [PubMed] 